\title{
The production of bactericidal fatty acids from glycerides in staphylococcal abscesses
}

\author{
T. R. SHRYOCK* and F. A. KAPRAL \\ Department of Medical Microbiology and Immunology, The Ohio State University, Columbus, OH 43210, USA
}

\begin{abstract}
Summary. Staphylococcal abscesses contain two types of lipids which are bactericidal for Staphylococcus aureus. These include a group of long chain unsaturated free fatty acids and another as yet unidentified lipid with unique properties. When abscess homogenates are incubated with $S$. aureus culture filtrates, the amount of bactericidal activity is increased. This phenomenon is called activation. To determine the source of increased bactericidal activity during activation, individual types of lipid were isolated from abscess homogenates and examined for their ability to be activated. Activation was found to result from the release of long chain unsaturated fatty acids from glycerides, presumably by the action of staphylococcal lipase.
\end{abstract}

\section{Introduction}

Previous studies have shown that the intraperitoneal inoculation of mice with Staphylococcus aureus results in the formation of typical abscesses that can be recovered free of extraneous tissue. ${ }^{1}$ The staphylococci within abscesses do not multiply but are generally eliminated, although at different rates depending upon the strain involved. ${ }^{1,2}$ The elimination of the organism involves the production of two types of bactericidal lipids. ${ }^{3,4}$ One of these is a pool of long chain unsaturated free fatty acids. The other lipid is unidentified at present, but possesses several properties that distinguish it from the fatty acids. ${ }^{5}$ The latter is more important in determining the survival of the staphylococci in abscesses whereas the fatty acids seem to serve a back-up role.

Staphylococcal strains differ in their sensitivity to the lipid. The most sensitive strains are rapidly eliminated from abscesses, whereas the more resistant strains are capable of persisting in abscesses for long periods. ${ }^{2}$ Strains of intermediate sensitivity are eliminated, but only after a delay of 7-10 days. This ability of the lipid to affect some strains more than others has been termed "differential activity" and is one of the characteristics that distinguish it from the bactericidal fatty acids. ${ }^{5}$

The lipid is produced only in staphylococcal abscesses and is not found in other tissues of normal or infected animals. ${ }^{4,6}$ However, abscess homogenates, after incubation with either live staphylococci or with staphylococcal culture filtrates, exhibit a

Received 21 March 1991 ; accepted 7 July 1991.

* Present address: Indiana State University, Terra Haute, IN 47809, USA. greater amount of bactericidal activity than is present initially. This phenomenon has been called "activation". 2,3 The purpose of this study was to explore the mechanism of activation and to determine which of the bactericidal lipids are generated by the process.

\section{Materials and methods}

\section{Staphylococcal strains}

S. aureus strain $18 \mathrm{Z}$, previously described, was used to initiate intraperitoneal abscesses. ${ }^{1}$ The organisms were grown for $24 \mathrm{~h}$ at $37^{\circ} \mathrm{C}$ in trypticase soy broth in oxygen $100 \%$ with constant shaking; the cells were harvested by centrifugation. The cocci were washed three times with a diluent consisting of saline with trypticase $0.1 \%$ and skimmed milk $0.1 \%$, and were then resuspended in the same diluent to give a final concentration of $c \cdot 10^{10} \mathrm{cocci} / \mathrm{ml}$. The suspensions were sealed in ampoules and stored at $-70^{\circ} \mathrm{C}$ until needed. Plate counts were done to confirm the bacterial concentration and viability at the time of preparation and again at the time of use.

S. aureus strains 303 and TG were used as indicator organisms in the bactericidal assay and have been described elsewhere. ${ }^{2,3}$ Strain 303 is very sensitive to the bactericidal lipid whereas strain TG is rather resistant. Both of these strains are about equally sensitive to any particular fatty acid. The indicator organisms were grown in trypticase soy broth for $8 \mathrm{~h}$ at $37^{\circ} \mathrm{C}$ with constant shaking and were resuspended in the same diluent to give a final concentration of c. $10^{7} \mathrm{cocci} / \mathrm{ml}$. These suspensions were also stored at $-70^{\circ} \mathrm{C}$ and counted as cfu before use. 


\section{Preparation of abscess homogenate}

Pelleted abscess homogenate was prepared as previously described. ${ }^{3}$ Groups of 20-30 female Swiss White ICR mice (Harlan/Sprague-Dawley, Inc. Indianapolis, IN, USA) weighing 25-30 g were inoculated intraperitoneally with $10^{9} \mathrm{cfu}$ of $S$. aureus $18 \mathrm{Z}$ in a volume of $0.25 \mathrm{ml}$. After 7 days, the abscesses were harvested, taking care not to include any extraneous fat or mesenteric tissue. The abscesses were homogenised in saline and the homogenates were centrifuged at $4^{\circ} \mathrm{C}$ at $40000 \mathrm{~g}$ for $20 \mathrm{~min}$. The supernatant fluid was discarded and the sediment together with the floating film were collected and washed three times in saline. The insoluble material was boiled for $30 \mathrm{~min}$ to eliminate residual viable cocci and was resuspended in saline ( $1 \mathrm{ml} / \mathrm{mouse})$. The homogenates were sealed in ampoules and stored at $-70^{\circ} \mathrm{C}$ until used.

\section{Activation of abscess homogenates and lipid fractions}

S. aureus $18 \mathrm{Z}$ was grown for $24 \mathrm{~h}$ at $37^{\circ} \mathrm{C}$ in trypticase soy broth with shaking in an atmosphere of oxygen $100 \%$. After centrifugation, the supernatant fluid was sterilised by filtration and stored in ampoules at $-70^{\circ} \mathrm{C}$ until needed. This culture filtrate was used for all these studies to initiate activation. In some studies, culture filtrate which had been boiled for $1 \mathrm{~h}$ was used as a control.

Activation of abscess homogenates was accomplished by mixing homogenates with five volumes of filtrate and incubating the mixture in a water bath at $37^{\circ} \mathrm{C}$ for $20-24 \mathrm{~h}$ with constant shaking. Samples of isolated lipid fractions were activated by dissolving the lipids in ethanol and diluting the solutions with 19 volumes of culture filtrate, and incubating the mixtures as before.

\section{Quantification of bactericidal activity}

The assay has been described in detail. ${ }^{2}$ Briefly, serial two-fold dilutions of abscess homogenates were made in a diluent consisting of $2 \mathrm{M} \mathrm{NaCl}$ with $2 \mathrm{~mm}$ edetic acid and an appropriate amount of indicator organism suspension was added. After incubation at $37^{\circ} \mathrm{C}$ for $1 \mathrm{~h}$, samples of each dilution were plated on trypticase soy agar and the surviving cocci were counted as cfu. Several tubes containing only diluent and organisms were included in each assay to serve as controls. Each assay was performed in duplicate.

Lipid fractions were assayed by dissolving samples in ethanol and diluting the solutions with 19 volumes of diluent. Additional two-fold serial dilutions in diluent were made as needed. Ethanol toxicity for the indicator organism was avoided as the final ethanol concentration in the first test dilution was only $2.5 \%$ and this concentration had no effect on the survival of $S$. aureus.

Fifty percent end points were determined by the method of probits. ${ }^{7}$ A bactericidal unit, LD50, was defined as that quantity of homogenate or lipid that destroyed $50 \%$ of the inoculum under the conditions described. For abscess homogenates, the concentration of bactericidal activity was expressed as LD50/ $\mathrm{ml}$, whereas with lipid fractions, activity was expressed as $\mu \mathrm{g} / \mathrm{LD} 50$.

Activation was monitored by a change in activity against the indicator strain $S$. aureus 303 . To evaluate expression of differential activity, samples were assayed with both $S$. aureus strains 303 and TG as indicator organisms. The ratio of the end-points obtained with these organisms was called the "differential activity" index.

\section{Isolation and fractionation of lipids}

Lipids were extracted from abscess homogenates by the Bligh and Dyer modification of the Folch procedure $^{8}$ and water soluble non-lipid contaminants were removed by partition chromatography on Sephadex G-25. ${ }^{9}$ Lipid samples were separated into major lipid classes by chromatography on silicic acid (Unisil) columns and eluting sequentially with chloroform, acetone, and methanol. ${ }^{10}$ The neutral lipids were further fractionated on Unisil columns by elution with increasing concentrations of ether in hexane. ${ }^{11}$ Each lipid fraction was dried under nitrogen and stored at $4^{\circ} \mathrm{C}$ in vacuo.

\section{Thin layer chromatography}

TLC was used to ascertain the purity of fractions collected after the separation of neutral lipids. Silica Gel G-coated glass plates were pre-cleaned with chloroform:methanol $(2: 1)$, dried, and activated for $1 \mathrm{~h}$ at $110^{\circ} \mathrm{C}$. Plates were chromatographed in a single direction with petroleum ether: ethyl ether:acetic acid $(70: 30: 1)$ and lipids were visualised by exposing the plates to iodine vapor. Lipid standards were included as necessary.

\section{Fatty acid analyses}

Methyl esters of fatty acids were generated by using diazomethane prepared from [N-methyl- $n^{1}$-nitro-Nnitrosoguanidine]-diazomethane (Aldrich) according to published methods. ${ }^{12}$ Samples were dissolved in carbon disulphide and separated on a column of Alltech CS-10 10\% on Chromosorb W-AW (100-200 mesh) in a Packard Model 428 gas chromatograph fitted with an automatic integrator.

\section{Results}

\section{Source of increased bactericidal activity during activation}

Whereas the total lipid pool and the neutral lipid fraction from abscesses could be activated, the 
glycolipid and phospholipid fractions could not (table I). Further separation of the neutral lipids resulted in three glyceride fractions and a free fatty acid fraction. Although the three glyceride fractions possessed little bactericidal activity before activation, all exhibited an increase in activity after activation. In contrast there was no increase in bactericidal activity of the free fatty acid fraction after activation.

Abscess homogenates exhibited the greatest degree of differential activity, but after extraction and fractionation of the lipids, there was a noticeable loss of differential activity (table I). More importantly, although activation resulted in an increase in bactericidal activity in the glyceride fractions, there was no concomitant increase in the differential activity.

In several instances, pools of abscess homogenate were first activated and then the lipids were extracted and fractionated. In these cases the neutral lipid and free fatty acid fractions were the only fractions that possessed bactericidal activity and the levels of activity in these fractions were similar to those of equivalent fractions obtained from homogenates before activation (table I). None of the glyceride fractions possessed bactericidal activity.

No activation occurred in samples incubated with boiled culture filtrate.

\section{Analysis of lipid extracted from abscess homogenate}

Samples of the same homogenate pools were extracted for lipids either before or after activation (table II). The total lipid extracts were rather similar in that they consisted of approximately neutral lipid $88 \%$, glycolipid $1 \%$ and phospholipid $10 \%$. The composition of the neutral lipid fraction obtained from homogenates before or after activation was also determined (table III). Approximately $1 \%$ of the neutral lipid fraction eluted with hexane and presumably consisted of hydrocarbons or squalene, but these compounds were not specifically identified. Another $2 \%$ of the total lipid eluted with hexane:ether $(99: 1)$ and consisted of cholesteryl esters and methyl esters. Triglycerides accounted for approximately $46 \%$ of the neutral lipid fraction before activation, but only $22 \%$ after activation. However, the levels of diglycerides and monoglycerides changed very little as a consequence of activation. On the other hand, the percentage of free fatty acids increased from $25 \%$ before activation to about $52 \%$ after activation.

\section{Characterisation of the free fatty acid pool}

Regardless of whether abscess homogenates were activated or not, the composition of the free fatty acid pools were similar (table IV). Linoleic, oleic and palmitic acid were present in greatest amounts, with lesser amounts of palmitoleic acid. Myristic, stearic, linolenic, and arachidonic acids were also present, but collectively comprised $<3 \%$ of the total fatty acid pool. From among the fatty acids present, bactericidal activity is associated primarily with the unsaturated

Table I. Bactericidal activity and differential activity of lipid fractions from abscess homogenates*

\begin{tabular}{|c|c|c|c|c|}
\hline \multirow{2}{*}{ Preparation } & \multicolumn{2}{|c|}{$\begin{array}{c}\text { Bactericidal activity } \\
(\mu \mathrm{g} / \mathrm{LD} 50)\end{array}$} & \multicolumn{2}{|c|}{$\begin{array}{l}\text { Differential activity } \\
\text { index } \dagger\end{array}$} \\
\hline & $\begin{array}{l}\text { before } \\
\text { activation }\end{array}$ & $\begin{array}{c}\text { after } \\
\text { activation }\end{array}$ & $\begin{array}{l}\text { before } \\
\text { activation }\end{array}$ & $\begin{array}{c}\text { after } \\
\text { activation }\end{array}$ \\
\hline Abscess homogenate & $\ldots$ & $\ldots$ & 14 & 18 \\
\hline Total lipid pool & 29 & $7 \cdot 8$ & $\ldots$ & $\ldots$ \\
\hline Neutral lipid fraction & 16 & $6 \cdot 3$ & $5 \cdot 4$ & $4 \cdot 6$ \\
\hline Glycolipids & $>125$ & $>125$ & $\ldots$ & $\ldots$ \\
\hline Phospholipids & $>125$ & $>125$ & $\ldots$ & $\ldots$ \\
\hline Triglycerides & 36 & 16 & $5 \cdot 1$ & $6 \cdot 5$ \\
\hline Diglycerides & 79 & 22 & $\ldots$ & $\ldots$ \\
\hline Monoglycerides & 58 & 20 & $\ldots$ & $\ldots$ \\
\hline Free fatty acids & $4 \cdot 1$ & $5 \cdot 2$ & $1 \cdot 6$ & $1 \cdot 5$ \\
\hline
\end{tabular}

* Average of 1-5 homogenate pools.

† The ratio of the end-point obtained with the sensitive 303 strain divided by the end-point obtained with the resistant TG strain.

Table II. Composition of lipids from abscess homogenates before and after activation*

\begin{tabular}{l|cccc}
\hline \multirow{2}{*}{$\begin{array}{c}\text { Activation } \\
\text { state }\end{array}$} & $\begin{array}{c}\text { Total lipid } \\
\text { recovered } \\
\text { (mg/ml of } \\
\text { homogenate) }\end{array}$ & $\begin{array}{c}\text { Neutral } \\
\text { lipids }\end{array}$ & Glycolipids & Phospholipids \\
\hline Before & 16.9 & 88.2 & 0.6 & 11.2 \\
After & 18.1 & 88.5 & 2.0 & 9.5 \\
\hline
\end{tabular}

* Average of 4-5 homogenate pools. 
Table III. Composition of the neutral lipid fraction before and after activation*

\begin{tabular}{l|cc}
\hline & \multicolumn{2}{|c}{ Percentage of neutral lipid } \\
\cline { 2 - 3 } Fraction & $\begin{array}{c}\text { before } \\
\text { activation }\end{array}$ & $\begin{array}{c}\text { after } \\
\text { activation }\end{array}$ \\
\hline Hydrocarbons, squalene & 1 & 1 \\
Cholesteryl and methyl & 2 & 2 \\
esters & 46 & 22 \\
Triglycerides & 14 & 11 \\
Diglycerides & 8 & 13 \\
Monoglycerides & 25 & 52 \\
Free fatty acids & & \\
\hline
\end{tabular}

* Average of 4-5 homogenate pools.

Table IV. Composition of the fatty acid fraction from abscess homogenates before and after activation*

\begin{tabular}{l|cc}
\hline \multirow{2}{*}{ Fatty acid } & \multicolumn{2}{|c}{ Percentage of fatty acid fraction } \\
\cline { 2 - 3 } & $\begin{array}{c}\text { before } \\
\text { activation }\end{array}$ & $\begin{array}{c}\text { after } \\
\text { activation }\end{array}$ \\
\hline Myristic & $0 \cdot 3$ & $0 \cdot 4$ \\
Palmitic & $19 \cdot 0$ & $20 \cdot 6$ \\
Stearic & $0 \cdot 5$ & $1 \cdot 9$ \\
Palmitoleic & $5 \cdot 4$ & $6 \cdot 1$ \\
Oleic & $30 \cdot 2$ & $30 \cdot 4$ \\
Linoleic & $41 \cdot 2$ & $38 \cdot 6$ \\
Linolenic & $0 \cdot 9$ & 0 \\
Arachidonic & $0 \cdot 3$ & $0 \cdot 3$ \\
Total & $97 \cdot 8$ & $98 \cdot 3$ \\
Total unsaturated fatty & & \\
acids & $78 \cdot 0$ & $75 \cdot 4$ \\
\hline
\end{tabular}

* Average of three abscess homogenate pools.

acids and these made up about $76 \%$ of the fatty acid fraction.

\section{Discussion}

Staphylococcal abscesses contain two kinds of lipid that express bactericidal activity towards $S$. aureus. Present in greatest amount is a pool of unsaturated long chain fatty acids which collectively comprise about $17 \%$ of the total lipid in abscesses (tables IIIV). The second is an unidentified lipid that constitutes $<1 \%$ of the total lipid pool. ${ }^{4}$ Although the chemical structure of this lipid has not been determined, several characteristics distinguish it from the long chain fatty acids. Firstly, it is about 100 times more active against staphylococci than the most active unsaturated fatty acids. ${ }^{4}$ Secondly, it manifests differential activity which is expressed by a differential activity index greater than 10 , i.e., it is $10-400$ times more active against certain $S$. aureus strains than against others. ${ }^{2}$ These first two properties cannot be mimicked by any of the long chain fatty acids either when present singly or when present in combination as they occur in abscesses. Thirdly, whereas most fatty acids are more active at an acid $\mathrm{pH},{ }^{13}$ the lipid exhibits no significant change in activity over the range $\mathrm{pH} 5 \cdot 5-9 \cdot 0$. Fourthly, unsaturated fatty acids lose their bactericidal activity upon catalytic reduction because they are converted to their saturated counterparts. However, catalytic reduction of the lipid does not alter its activity. Finally, whereas unsaturated fatty acids tend to become more toxic for bacteria after oxidation or peroxidation, ${ }^{14}$ its activity is completely destroyed upon oxidation.

The increase in bactericidal activity seen after activation could result from the production of either more lipid or more long chain unsaturated fatty acids. If more lipid were produced not only would the bactericidal activity increase, but also the differential activity index would remain greater than 10 . On the other hand if activation resulted from the production of free fatty acids, then the bactericidal activity would increase while the differential activity index would decrease. When lipids extracted from abscess homogenates were fractionated into major lipid classes, only the neutral lipid fraction could be activated (table I). Subsequent fractionation of the neutral lipids revealed that activation was limited to the glyceride fractions. However, concomitant with an increase in bactericidal activity there was a decrease in the differential activity index. This suggested that fatty acids released by the hydrolysis of glycerides were responsible for the increased bactericidal activity seen after activation. When examined by TLC, the activated glyceride fractions revealed the presence of fatty acids whereas the same glyceride fractions before activation did not. Moreover, after activation of abscess homogenates, there was a $50 \%$ decrease in the amount of triglycerides present and a corresponding increase in the amount of free fatty acids (table III). These findings also suggested that the hydrolysis of glycerides was probably due to lipase activity. In this regard, it is worth noting that more than $99 \%$ of $S$. aureus strains produce lipase ${ }^{15}$ and that, specifically, $S$. aureus $18 \mathrm{Z}$, the strain used for activation, is a known lipase producer.

Although there was a marked reduction in the triglyceride content after activation, the diglyceride and monoglyceride concentrations remained relatively unchanged (table III). Although this might reflect a preferential hydrolysis of triglycerides by the lipase it is more likely that hydrolysis, which would result in the production of di- and monoglycerides as intermediates, was as yet incomplete when samples were taken. It should be noted that the conditions existing during activation are not conducive for maximal lipase activity. ${ }^{16}$ If the $\mathrm{pH}$ and calcium concentration were adjusted to optimum values, then culture filtrates could completely hydrolyse the glycerides in less than $2 \mathrm{~h}$.

The free fatty acid fraction obtained from activated homogenates was not noticeably different in bactericidal activity or in composition when compared with that obtained from non-activated homogenates (tables I and IV). The fact that the composition of the fatty acid pool remained unchanged after activation sug- 
gests that the glycerides might be the source of the fatty acids initially present in the abscesses. Hydrolysis of glycerides could possibly result from the action of leucocyte lipases ${ }^{17}$ or from staphylococcal lipase. Recent studies (Chamberlain and Kapral, unpublished) with immunohistochemical techniques have

\section{References}

1. Kapral FA, Godwin JR, Dye ES. Formation of intraperitoneal abscesses by Staphylococcus aureus. Infect Immun 1980; 30: 204-211.

2. Dye ES, Kapral FA. Survival of Staphylococcus aureus in intraperitoneal abscesses. J Med Microbiol 1981 ; 14 : 185194.

3. Dye ES, Kapral FA. Partial characterization of a bactericidal system in staphylococcal abscesses. Infect Immun 1980; 30: 198-203.

4. Dye ES, Kapral FA. Characterization of a bactericidal lipid developing within staphylococcal abscesses. Infect Immun 1981; 32: 98-104.

5. Kapral FA, Mortensen JE. Mechanisms of resistance to staphylocidal fatty acids in abscesses. In: Jeljaszewicz $\mathbf{J}$ (ed) The staphylococci. Zentralbl Bakteriol Mikrobiol Hyg 1984; Suppl 14: 507-509.

6. Kapral FA, Dye ES. A bactericidal system responsible for the destruction of Staphylococcus aureus within abscesses. In: Jeljaszewicz J (ed) Staphylococci and staphylococcal infections. Zentralbl Bakteriol Mikrobiol Hyg 1981: Suppl $10841-845$.

7. Finney DJ. Probit analysis, 3rd edn. Cambridge, Cambridge University Press. 1971.

8. Bligh EG, Dyer WJ. A rapid method of total lipid extraction and purification. Can J Biochem Physiol 1959; 37: 911-917. shown that lipase is indeed secreted by $S$. aureus within abscesses.

This investigation was supported by US Public Health Service Grants AI-7826 and AI-19879 from the National Institute of Allergy and Infectious Disease.

9. Rouser G, Kritchevsky G, Yamamoto A. Column chromatographic and associated procedures for separation and determination of phosphatides and glycolipids. In: Marinetti GV (ed) Lipid chromatographic analysis, vol 1. New York, Marcel Dekker. 1967: 99-162.

10. Kates M. Techniques of lipidology: isolation, analysis and identification of lipids. Amsterdam, North-Holland Publishing Company. 1972.

11. Carroll KK, Serdarevich B. Column chromatography of neutral glycerides and fatty acids. In: Marinetti GV (ed) Lipid chromatographic analysis, vol 1. New York, Marcel Dekker. 1967: 205-237.

12. Fales HM, Jaouni TM, Babashak JF. Simple device for preparing ethereal diazomethane without resorting to codistillation. Anal Chem 1973; 45: 2302-2303.

13. Kanai $K$, Kondo $E$. Antibacterial and cytotoxic aspects of long chain fatty acids as cell surface events: selected topics (a review). Jpn J Med Sci Biol 1978; 32: 135-174.

14. Gutteridge JMC, Lamport P, Dormandy TL. Autoxidation as a cause of antibacterial activity in unsaturated fatty acids. J Med Microbiol 1974; 7 : 387-389.

15. Elek SD. Staphylococcus pyogenes: and its relation to disease. Edinburgh, E and S Livingstone. 1959.

16. Tyski S, Hryniewicz W, Jaljaszewicz J. Purification and some properties of the staphylococcal extracellular lipase. Biochem Biophys Acta 1983; 749: 312-317.

17. Movat $\mathrm{HZ}$ (ed). Inflammation, immunity and hypersensitivity. New York, Harper and Row. 1971: 82-87. 